\title{
Vertical Mammaplasty for Varying Degrees of Reduction
}

\author{
Daejin Kim ${ }^{1}$, Seo-young Kim², \\ Daegu Son ${ }^{2}$ \\ ${ }^{1}$ Dr. Kim Plastic Surgery, Pohang; \\ ${ }^{2}$ Department of Plastic and \\ Reconstructive Surgery, Institute for \\ Medical Science, Keimyung University \\ School of Medicine, Daegu, Korea
}

This article was presented at the 69th Congress of the Korean Society of Plastic and Reconstructive Surgeons on November 11-13, 2011, in Seoul, Korea.

\section{Acknowledgements: The author wishes to thank Dr. Aram Harijan for his insightful comments and Dr. Xiao Yang for her excep- tional drawings.}

No potential conflict of interest relevant to this article was reported.

\begin{abstract}
Background Vertical reduction mammaplasty has been criticized for its inability to address larger cases of mammary hypertrophy, with a relatively high frequency of sensory loss reported. This article describes our single-institution experience with modified vertical reduction mammaplasty for varying degrees of breast reduction.

Methods Thirty-three patients underwent breast reduction using the modified vertical reduction mammaplasty technique with a superomedial dermoglandular pedicle and modifications involving breast parenchyma excision. The degree of sensory preservation in the nipple-areola complex (NAC) was compared with preoperative sensation using an ordinal scale (0, insensate; 10, unchanged). Postoperative outcomes were evaluated through a photogrammetric analysis. Satisfaction with postoperative outcomes was assessed using a telephone questionnaire survey (1, very poor; 5 , very good).

Results The modified vertical mammaplasty technique allowed for reductions of up to 1,800 g per side. The mean resection weight was $459.24 \mathrm{~g}$ per breast (range, $76-1,800$ g). Of the 59 operations, 9 involved complications without significant morbidity. The sensibility of the NAC recovered in most patients by 5 months after the operation. The mean satisfaction score was 3.4, which was between 'no change' and 'satisfied.' Conclusions Modified vertical reduction mammaplasty allows a single surgeon to address varying degrees of breast hypertrophy.
\end{abstract}

Keywords Gigantomastia, Mammaplasty, Nipples

\section{INTRODUCTION}

Vertical scar reduction mammaplasty, as described by Lassus [1] and popularized by Lejour [2], has not achieved widespread acceptance, and is considered to have certain limitations by many. Among the various modifications to vertical reduction mammaplasty that have been reported, the most clinically significant was described by Hall-Findlay [3], who showed that the use of a superomedial der-

Received: Aug 6, 2016 Revised: Oct 1, 2016 Accepted: Oct 4, 2016 Correspondence: Daegu Son Department of Plastic and Reconstructive Surgery, Institute for Medical Science, Keimyung University School of Medicine, 56, Dalseong-ro, Jung-gu, Daegu 41931, Korea.

E-mail: handson@dsmc.or.kr

Copyright @ 2016 The Korean Society for Aesthetic Plastic Surgery.

This is an Open Access article distributed under the terms of the Creative Commons Attribution Non-Commercial License (http://creativecommons.org/licenses/by-nc/4.0/) which permits unrestricted non-commercial use, distribution, and reproduction in any medium, provided the original work is properly cited. $\quad$ www.e-aaps.org moglandular pedicle led to better outcomes and fewer complications.

Despite-or perhaps because of-this change in the pedicle, the Hall-Findlay vertical mammaplasty [3] was limited to breasts requiring resections of less than $1,100 \mathrm{~g}$ per breast and/or with mild to moderate mastoptosis (less than $30 \mathrm{~cm}$ from sternal notch to nipple). A relatively high frequency of sensory loss in the nippleareola complex (NAC) has also been reported [4].

The goal of reduction mammaplasty is achieved when the resulting shape and size of the breasts is satisfactory to the patient and when sensation in the NAC is preserved. Moreover, it is preferable if the operation can be performed using a single method regardless of the size of the breast.

In this study, we present our single-institution experience with the use of a vertical mammaplasty with refinements involving the superomedial dermoglandular pedicle. This article describes a surgical technique performed by a single surgeon, including an evaluation of the postoperative results. 


\section{METHODS}

\section{Patients}

This retrospective study was approved by the Institutional Review Board. A single-institution retrospective review was performed for all patients who underwent vertical reduction mammaplasty between April 2004 and June 2013. Each patient underwent a typical preoperative evaluation for reduction mammaplasty, including photogrammetric analysis. After the operations, patients received follow-up at our outpatient clinic, where postoperative photographs were obtained and sensory recovery evaluated. Additionally, follow-up telephone surveys were used to evaluate patient satisfaction.

\section{The modified mammaplasty design}

The mammaplasty design was made with the patient in standing position, as described by Hall-Findlay [3], with modifications by others [4-6]. Previously, the NAC was marked with a cookie cutter $45 \mathrm{~mm}$ in diameter, but we designed the planned circumference of the NAC utilizing a new mosque pattern. A malleable wire of appropriate size $(16,17$, or $19 \mathrm{~cm})$ was used to draw a parabolic curve that would eventually become the circumferential areola margin. For instance, a 16-cm long wire was used to design an areola with a diameter of $45 \mathrm{~mm}$ ( $\pi \times$ diameter). Variations in the parabolic curve allowed control of projection. The malleable wire could be bent to produce a narrower or wider areola margin for increased or decreased projection, respectively (Fig. 1). The amount of breast parenchyma to be resected was determined by the vertical limb. When designing the lateral and medial vertical limit, the extent of the resection could be controlled by pushing harder when more reduction was requested and pushing less when less reduction was necessary. Care should be taken when designing the medial vertical limit because problems such as scar widening may develop due to the tension on the medial portion (sternum). The two vertical incision lines are joined in a $U$ shape, with the bottommost portion approximately 4 to $5 \mathrm{~cm}$ above the inframammary fold. To prevent the vertical scar from extending below the inframammary fold line, the design length was limited to less than $5 \mathrm{~cm}$.

In most cases, superomedial pedicles were employed. Superior pedicles were used for smaller breasts, and medial pedicles were reserved for larger breasts (Fig. 2). For larger breasts, the superomedial dermoglandular pedicle base (approximately 6-8 cm) extended deep to the vertical limb, with only 1 to $2 \mathrm{~cm}$ of the pedicle base running beneath the areolar opening (Fig. 2).

\section{Operative technique}

The method of vertical reduction mammaplasty was partially based on the technique described by Hall-Findlay [3], with modifications by others [4-6].

To protect the lateral branch of the fourth intercostal nerve, much of the soft tissue above the pectoralis fascia was left in place. The tissue was left at full thickness without any undermining deep to the pedicle. At the fourth intercostal level, the resection was carried out laterally for relatively small (200-400 g) reductions. Additional beveled sections were removed laterally as needed for larger reductions ( $>600 \mathrm{~g}$ ). Resections were carried as far out laterally as possible without compromising the lateral portion of the skin flap (Fig. $3 \mathrm{~A})$. Below the fourth intercostal space and the level of the lateral branch, the main bulk of resection took place in the central portion of the breast, with additional beveled sections taken both medially and laterally (Fig. 3B).

The inferior portion of the skin flap was undermined down to the inframammary fold with medial and lateral extensions to the
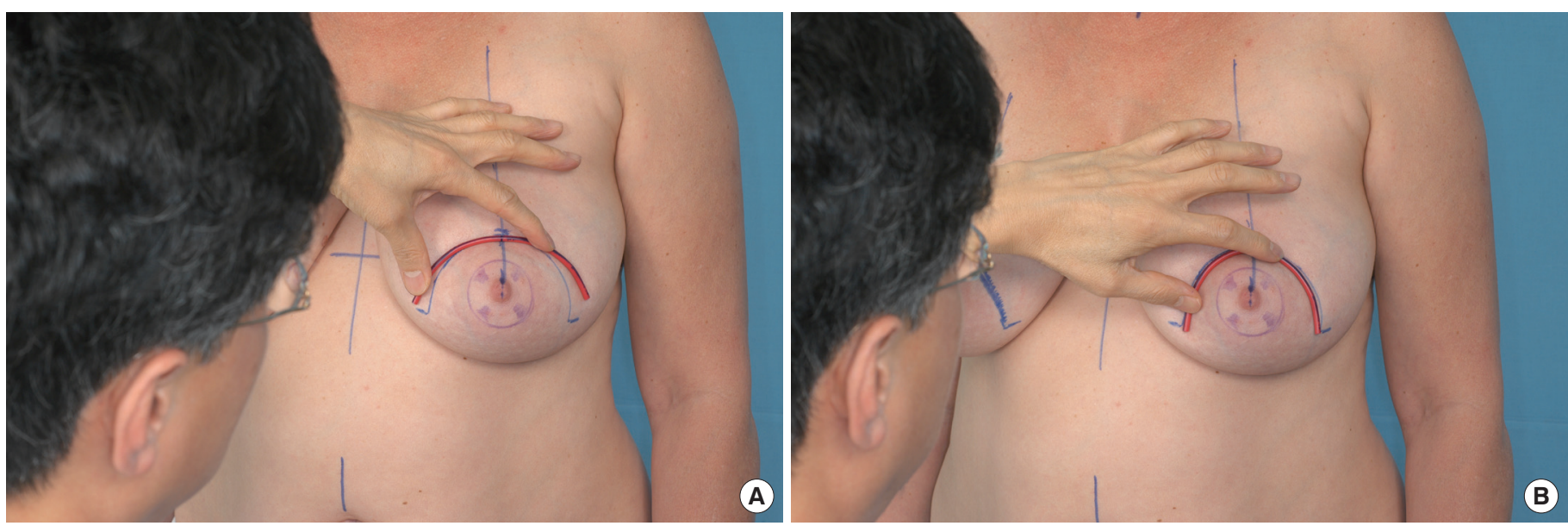

Fig. 1. Preoperative mosque dome design. The preoperative modified mosque dome (areolar opening) skin markings are shown. Instead of the more traditional rendering of a key-hole shape opening to determine the future position and shape of the areola, a variable opening for the areola was drawn using malleable wire. (A) If more projection was needed, the wire was widened. (B) If less projection was needed, the malleable wire was narrowed to achieve better coning and increased projection. 
vertical limbs to prevent contour irregularities and dog-ear formation on the most inferior portion. A buffer of fatty tissue measuring approximately $1 \mathrm{~cm}$ is adequate to minimize skin necrosis in this area.

After insetting the areola, the medial pillar and lateral pillar were brought together for shaping. For gigantomastia, the incision was extended laterally and medially to prevent the extension of the vertical scar to the inframammary fold.

\section{Degree of sensory preservation in the NAC}

The NAC was assessed in 18 patients during postoperative clinic visits. Patients were instructed to self-evaluate NAC sensation by
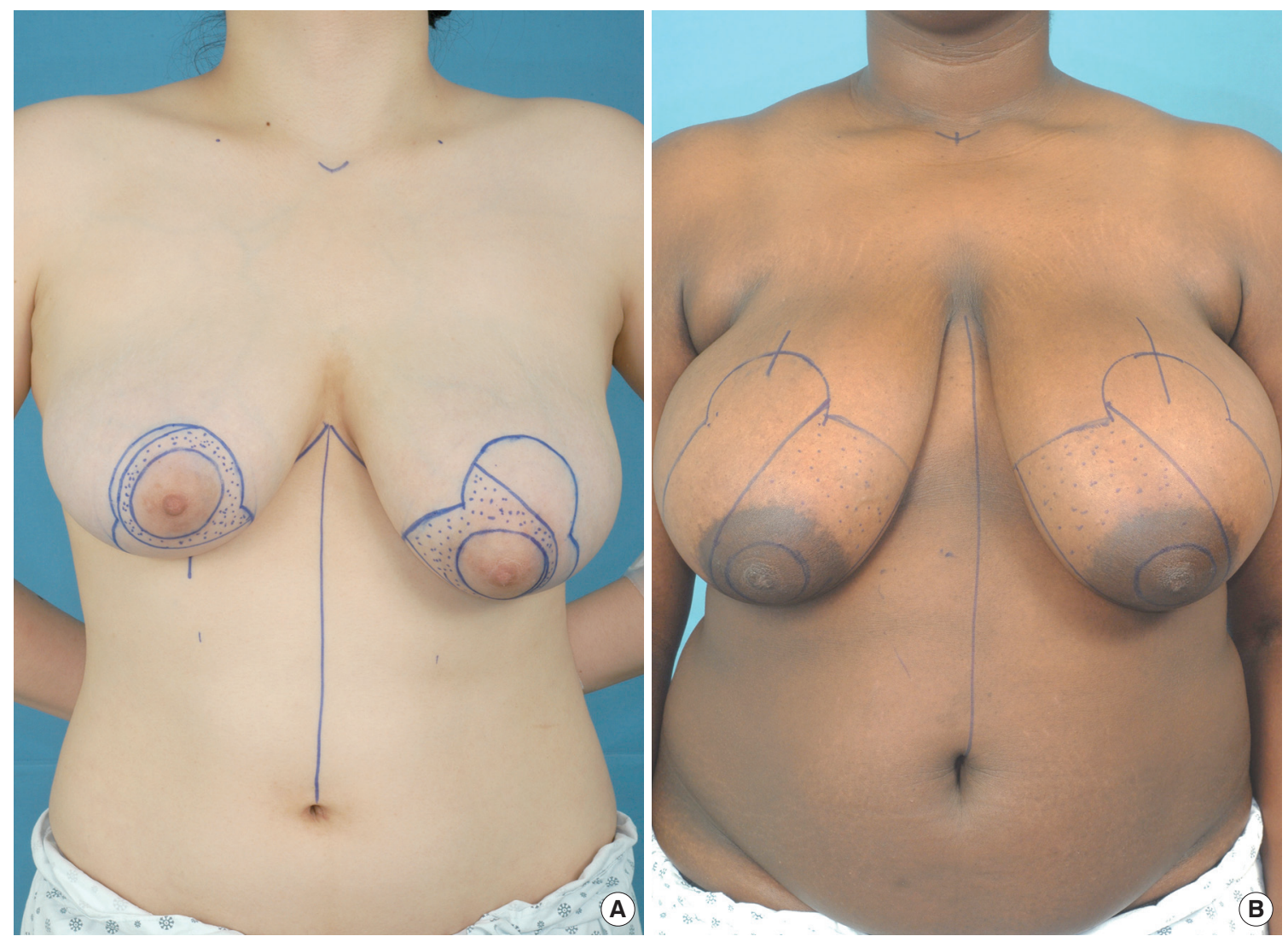

Fig. 2. (A) Design of the superomedial pedicles. According to breast size, the pedicle is superior, superomedial, (B) or medial. (B) In large breasts, the base of the pedicle was 1 to $2 \mathrm{~cm}$ into the areolar opening, and the other end of the pedicle onto the vertical limb.

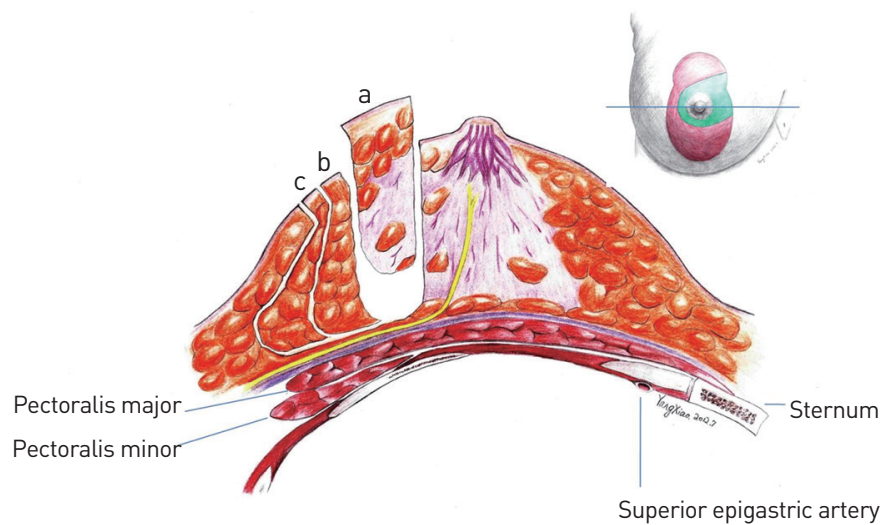

A

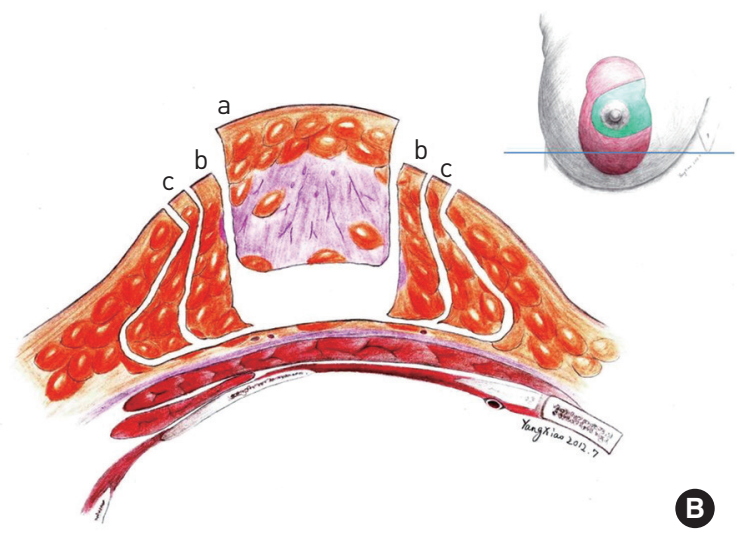

Fig. 3. Design of the dermoglandular resection patterns. Resection patterns varied with the volume of the reduction (a, b, c). (A) Resection patterns at the pedicle level. (B) Resection patterns at the sub-pedicle level. 
manual touch. The degree of sensory preservation in the NAC was compared with the preoperative sensibility using an ordinal scale from 0 (insensate) to 10 (no change in sensation) [7].

\section{Photogrammetry analysis}

Postoperative outcomes were assessed in 19 patients using photographs. All photographs were obtained in a standard clinical photographic view in the same anatomical position. Anthropometry

Table 1. Telephone questionnaire survey ( $n=10)$

\begin{tabular}{|c|c|c|c|c|c|}
\hline \multicolumn{6}{|c|}{ Postoperative satisfaction survey } \\
\hline 1.1 While clothed, are you satisfied with... & $\square$ & $\square$ & $\square$ & $\square$ & $\square$ \\
\hline 1.1.1 Your overall appearance in the mirror? & $\square$ & $\square$ & $\square$ & $\square$ & $\square$ \\
\hline 1.1.2 Your appearance when wearing a bra? & $\square$ & $\square$ & $\square$ & $\square$ & $\square$ \\
\hline 1.1.3 The feel of clothes over the breasts? & $\square$ & $\square$ & $\square$ & $\square$ & $\square$ \\
\hline 1.1.5 The fit of the clothes? & $\square$ & $\square$ & $\square$ & $\square$ & $\square$ \\
\hline 1.2 While undressed, are you satisfied with... & $\square$ & $\square$ & $\square$ & $\square$ & $\square$ \\
\hline 1.2.1 The decrease in the size of the breasts? & $\square$ & $\square$ & $\square$ & $\square$ & $\square$ \\
\hline 1.2.2 The symmetry of the shape of the breasts? & $\square$ & $\square$ & $\square$ & $\square$ & $\square$ \\
\hline 1.2.3 The symmetry of the size of the breasts? & $\square$ & $\square$ & $\square$ & $\square$ & $\square$ \\
\hline 1.2.7 The overall appearance of the bare breasts? & $\square$ & $\square$ & $\square$ & $\square$ & $\square$ \\
\hline
\end{tabular}

\begin{tabular}{|c|c|c|c|c|c|}
\hline 2. Postoperative incision scar & (5) Very satisfied & (4) Satisfied & (3) No change & (2) Dissatisfied & (1) Very dissatisfied \\
\hline 2.2 Width of the scar & $\square$ & $\square$ & $\square$ & $\square$ & $\square$ \\
\hline 3. Symptoms & (5) Very satisfied & (4) Satisfied & (3) No change & (2) Dissatisfied & (1) Very dissatisfied \\
\hline 3.1 Changes in pain & $\square$ & $\square$ & $\square$ & $\square$ & $\square$ \\
\hline 3.1.3 Back & $\square$ & $\square$ & $\square$ & $\square$ & $\square$ \\
\hline 3.1.4 Breast & $\square$ & $\square$ & $\square$ & $\square$ & $\square$ \\
\hline 3.2 Changes in skin & $\square$ & $\square$ & $\square$ & $\square$ & $\square$ \\
\hline 3.2.1 Improvements in intertrigo & $\square$ & $\square$ & $\square$ & $\square$ & $\square$ \\
\hline 3.4 Shoulder indentations from bra straps & $\square$ & $\square$ & $\square$ & $\square$ & $\square$ \\
\hline
\end{tabular}

\begin{tabular}{|c|c|c|c|c|c|}
\hline 4. Improvements during exercise/activity & (5) Very satisfied & (4) Satisfied & (3) No change & (2) Dissatisfied & (1) Very dissatisfied \\
\hline 4.2 Static activities, such as bending and picking up objects & $\square$ & $\square$ & $\square$ & $\square$ & $\square$ \\
\hline 5. Overall satisfaction & (5) Very satisfied & (4) Satisfied & (3) No change & (2) Dissatisfied & (1) Very dissatisfied \\
\hline 5.1 Satisfied with the decision to undergo surgery & $\square$ & $\square$ & $\square$ & $\square$ & $\square$ \\
\hline
\end{tabular}


was assessed using Photoshop CS5 (Adobe. San Jose, CA, USA). Breast symmetry was compared between the preoperative and postoperative photographs.

\section{Telephone questionnaire survey}

The survey evaluated 5 categories of patient-centric perceptions of the surgical intervention, consisting of satisfaction levels regarding overall appearance, scar appearance, symptoms, activity, and the operation itself. Each of the categorical items was evaluated using an ordinal scale of 1 (very dissatisfied) to 5 (very satisfied) (Table 1) [7].

\section{Statistical analysis}

All statistical analyses were performed using SPSS version 16.0 (SPSS Inc., Chicago, IL, USA). P-values less than 0.05 in the paired $\mathrm{t}$-test were considered to indicate statistical significance.

\section{RESULTS}

This review identified 33 patients as having undergone the modified vertical reduction mammaplasty technique described above. Twenty-five patients ( 43 breasts) were ethnic Koreans. The remaining 8 patients ( 16 breasts) were American military service personnel, among whom 3 were African-American and 5 were Caucasian. The patients' mean age was $41.7 \pm 11.8$ years, with a mean follow-up period of 8.9 months. The patients' mean body mass index (BMI) was $26.5 \mathrm{~kg} / \mathrm{m}^{2}$. None of the patients had comorbidities such as diabetes mellitus or coronary artery disease. However, 6 patients had hypertension, and 7 had unilateral breast cancer (Table 2). The amount of resected tissue was $<200 \mathrm{~g}$ in 8 breasts (6 patients), 200$400 \mathrm{~g}$ in 18 breasts (8 patients), 400 to $600 \mathrm{~g}$ in 22 breasts (12 patients), and $>600 \mathrm{~g}$ in 11 breasts (7 patients). The proportion of patients requiring resections of more than $600 \mathrm{~g}$ was higher for the American patients than for the Korean patients (37.5\% vs. $11.6 \%$, respectively) (Table 3 ).

No instances of postoperative hematoma, seroma, skin necrosis, or infection were observed (Table 4). The most common complication was dog-ear formations $(n=5,8.47 \%)$ at the inferior aspect of the incision, for which scar revision was performed 6 months postoperatively. Wound dehiscence occurred in a single patient with a BMI of 38.94. Daily dressing changes were sufficient for closing the wound by secondary intention.

\section{Degree of sensory preservation in the NAC}

Of the 33 patients, 18 patients were followed up. The amount of tissue removed was 200 to $400 \mathrm{~g}$ per breast in 6 patients, 400 to 600 $\mathrm{g}$ in 7 patients, and $>600 \mathrm{~g}$ in 5 patients. Among these 18 patients, 9 responded to the telephone survey and reported satisfactory sensory recovery at a mean follow-up period of 5 months. The maxi-

Table 2. Baseline characteristics of the study participants

\begin{tabular}{|c|c|}
\hline Patients, n & 33 \\
\hline Breasts, $\mathrm{n}$ & 59 \\
\hline Mean age (SD), year & $41.67(11.75)$ \\
\hline \multicolumn{2}{|l|}{ Patient background } \\
\hline Korean, n [\%] & $25(75.76)$ \\
\hline American, $\mathrm{n}(\%)$ & $8(24.24)$ \\
\hline Black, n (\%) & $5(15.15)$ \\
\hline White, $\mathrm{n}(\%)$ & $3(9.09)$ \\
\hline \multicolumn{2}{|l|}{ Comorbidities } \\
\hline Hypertension, n (\%) & $6(18.18)$ \\
\hline Diabetes mellitus, $\mathrm{n}(\%)$ & $0(0)$ \\
\hline \multicolumn{2}{|l|}{ Obesity } \\
\hline Korea (BMI > 25), n (\%) & $21(63.64)$ \\
\hline WHO (BMI >30), n (\%) & $4(12.12)$ \\
\hline \multicolumn{2}{|l|}{ Breast cancer (unilateral) } \\
\hline Total, n (\%) & $7(21.21)$ \\
\hline Right, n (\%) & $3(9.09)$ \\
\hline Left, n (\%) & $4(12.12)$ \\
\hline IDC, $\mathrm{n}(\%)$ & $4(12.12)$ \\
\hline DCIS, n (\%) & $3(9.09)$ \\
\hline Smokers, n (\%) & $0(0)$ \\
\hline Mean weight (SD), kg & $66.35(10.87)$ \\
\hline Mean height (SD), m & $1.58(0.052)$ \\
\hline Mean BMI (SD) & $26.48(3.99)$ \\
\hline Mean follow-up duration (SD), month & $8.92(8.87)$ \\
\hline \multicolumn{2}{|l|}{ Reduction amounts } \\
\hline Mean total, g & $459.24(76-1,800)$ \\
\hline Mean right, g & $452.17(76-1,450)$ \\
\hline Mean left, g & $466.55(90-1,800)$ \\
\hline
\end{tabular}

SD, standard deviation; BMI, body mass index; WHO, World Health Organization; IDC, invasive ductal carcinoma; DCIS, ductal carcinoma in situ.

Table 3. Reduction amounts

\begin{tabular}{|c|c|c|c|c|c|c|}
\hline Reduction amounts & \multicolumn{2}{|c|}{ Total ( $n=33,59$ breasts) } & \multicolumn{2}{|c|}{ Korean ( $n=25,43$ breasts) } & \multicolumn{2}{|c|}{ American ( $\mathrm{n}=8,16$ breasts) } \\
\hline$<200 \mathrm{~g}$ & $6(18.18)$ & $8(13.56)$ & $5(20)$ & $6(13.95)$ & $1(12.5)$ & $2(12.5)$ \\
\hline $200-400 \mathrm{~g}$ & 8 (24.24) & $18(30.51)$ & $4(16)$ & $10(23.26)$ & $4(50)$ & $8(50)$ \\
\hline $400-600 \mathrm{~g}$ & $12(36.36)$ & 22 (37.29) & $12(48)$ & $22(51.16)$ & $0(0)$ & $0(0)$ \\
\hline$>600 \mathrm{~g}$ & $7(21.21)$ & $11(18.64)$ & $4(16)$ & $5(11.63)$ & 3 (37.5) & $6(37.5)$ \\
\hline
\end{tabular}


Table 4. Postoperative complications in 59 breasts

\begin{tabular}{ll}
\hline Postoperative evaluation & Breasts, $\mathrm{n}(\%)$ \\
\hline Complication & $0(0)$ \\
Seroma & $0(0)$ \\
Hematoma & $0(0)$ \\
Infection & $0(0)$ \\
Skin necrosis & $2(3.39)$ \\
Delayed wound healing & $2(3.39)$ \\
Hypertrophic scar & $5(8.47)$ \\
Dog ear & $0(0)$ \\
Loss of sensation in the NAC &
\end{tabular}

NAC, nipple-areola complex.

\begin{tabular}{|c|c|c|c|c|c|c|c|c|c|c|}
\hline \begin{tabular}{|c|} 
Case Month \\
(reduction g)
\end{tabular} & 0 & 1 & 2 & 3 & 4 & 5 & 6 & 7 & $\cdots$ & 12 \\
\hline $\begin{array}{c}1 \\
(450 / 435) \\
\end{array}$ & $5 / 6$ & & & $8 / 8$ & & & & $10 / 10$ & & \\
\hline$\stackrel{2}{2}$ & $6 / 7$ & & & $8 / 8$ & & & & & & $10 / 10$ \\
\hline $\begin{array}{c}3 \\
(500 / 400)\end{array}$ & $5 / 10$ & & & & & $10 / 10$ & & & & \\
\hline $\begin{array}{c}4 \\
(575 / 560)\end{array}$ & & $11 / 11$ & & & & & & & & \\
\hline $\begin{array}{c}5 \\
(448 / 322)\end{array}$ & $10 / 10$ & & & & & & & & & \\
\hline $\begin{array}{c}6 \\
(445 / 450)\end{array}$ & $8 / 5$ & & $9 / 8$ & $10 / 10$ & & & & & & \\
\hline $\begin{array}{c}7 \\
(680 / 510)\end{array}$ & $10 / 10$ & & & & & & & & & \\
\hline $\begin{array}{c}8 \\
840 / 994)\end{array}$ & & & & & & & & $11 / 11$ & & \\
\hline $\begin{array}{c}9 \\
(276 / 288)\end{array}$ & $7 / 10$ & & & $10 / 10$ & & & & & & \\
\hline $\begin{array}{c}10 \\
(640 / 490)\end{array}$ & $5 / 8$ & & & & $10 / 10$ & & & & & \\
\hline $\begin{array}{c}11 \\
1992(562)\end{array}$ & $10 / 10$ & & & & & & & & & \\
\hline $\begin{array}{c}12 \\
(224 / 316)\end{array}$ & $4 / 9$ & & & & $8 / 10$ & $10 / 10$ & & & & \\
\hline $\begin{array}{c}13 \\
(602 / 605)\end{array}$ & $8 / 8$ & & & & & $10 / 10$ & & & & \\
\hline $\begin{array}{c}14 \\
(916 / 952)\end{array}$ & 9/9 & & $10 / 10$ & & & & & & & \\
\hline $\begin{array}{c}15 \\
(240 / 245)\end{array}$ & $7 / 5$ & & & & & $8 / 7$ & & & & $10 / 10$ \\
\hline $\begin{array}{c}16 \\
(390 / 360)\end{array}$ & $11 / 11$ & & & & & & & & & \\
\hline $\begin{array}{c}17 \\
(98 / 108)\end{array}$ & $11 / 10$ & $10 / 10$ & & & & & & & & \\
\hline $\begin{array}{c}18 \\
(130 / 115)\end{array}$ & $10 / 10$ & & & & & & & & & \\
\hline
\end{tabular}

Fig. 4. Survey assessing the degree of sensory preservation in the nipple-areola complex (right/left score). Although $64.2 \%$ of the survey respondents indicated scores of 0 to 9 on a scale ranging from 0 to 10 , where 10 referred to unchanged sensibility, all respondents reported restored sensibility by 12 months, with recovery of sensibility taking place at a mean of 5 months.

mum recovery period was 12 months. Four of the 18 patients reported sensory improvement at both 1- and 6-month follow-up appointments (Fig. 4).

\section{Photogrammetric analysis}

Photogrammetric analysis was possible for 19 patients, among whom the amount of reduction was 200 to $400 \mathrm{~g}$ per breast in 5 patients, 400 to $600 \mathrm{~g}$ in 9 patients, and $>600 \mathrm{~g}$ in 5 patients. Anthropometric assessments revealed statistically significant improvements in breast symmetry (Table 5, Fig. 5 and 6).
Table 5. Photogrammetric analysis ( $n=19$ )

\begin{tabular}{lccc}
\hline & $\begin{array}{c}\text { Preoperative } \\
\text { Rt./Lt. ratio (SD) }\end{array}$ & $\begin{array}{c}\text { Postoperative } \\
\text { Rt./Lt. ratio (SD) }\end{array}$ & P-value \\
\hline SSN-N & $0.991 \pm 0.00854$ & $0.999 \pm 0.00289$ & $0.002^{\text {al }}$ \\
N-midline & $0.988 \pm 0.01063$ & $0.999 \pm 0.00939$ & $0.006^{\text {al }}$ \\
N-In & $1.069 \pm 0.06531$ & $0.969 \pm 0.02427$ & $0.002^{\text {al }}$ \\
BW & $1.0047 \pm 0.00615$ & $1.0042 \pm 0.00216$ & $0.001^{\text {al }}$ \\
BH & $1.011 \pm 0.01513$ & $0.994 \pm 0.00731$ & $0.001^{\text {al }}$ \\
Br-inclination & $1.023 \pm 0.00918$ & $0.983 \pm 0.00557$ & $0.001^{\text {al }}$ \\
\hline
\end{tabular}

Rt., right; Lt., left; SD, standard deviation; SSN, suprasternal notch; N, nipple; $\mathrm{N}$-midline, $\mathrm{N}$ to midline of anterior chest; $\mathrm{N}$-In, lowest point on inframmary crease; BW, breast width (lateral endpoint of the breast to medial endpoint of the breast); $\mathrm{BH}$, breast height (superior endpoint of the breast to lowest point on inframmary crease); Br-inclination, breast-inclination (angle between the anterior endpoint of the axilla to nipple and the vertical line of the anterior endpoint of the axilla).

${ }^{\text {al }}$ Paired t-test.
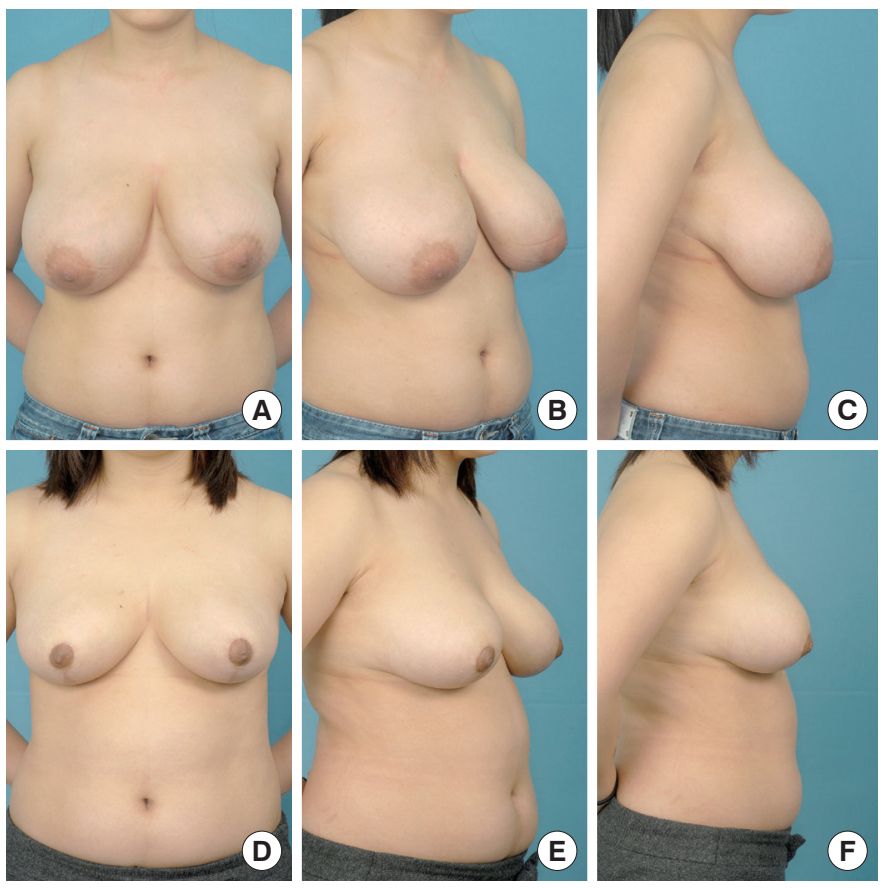

Fig. 5. A case of a reduction mammaplasty. A 25-year-old female patient underwent a total resection of 1,190 g (right, $680 \mathrm{~g}$; left, 510 g). (A, B, C) Preoperative views. (D, E, F) Twelve-month postoperative views.

\section{Telephone survey}

Ten patients agreed to participate in the telephone survey. In this group, the amount of reduction was 200 to $400 \mathrm{~g}$ per breast in 3 patients, 400 to $600 \mathrm{~g}$ in 4 patients, and $>600 \mathrm{~g}$ in 3 patients. The patients assessed their overall postoperative appearance with an average score of 3.4, between 'no change' and 'satisfied.' Similarly, satisfaction levels with clothed and undressed postoperative appearance were rated 3.58 and 3.22, respectively. Patients assessed their 

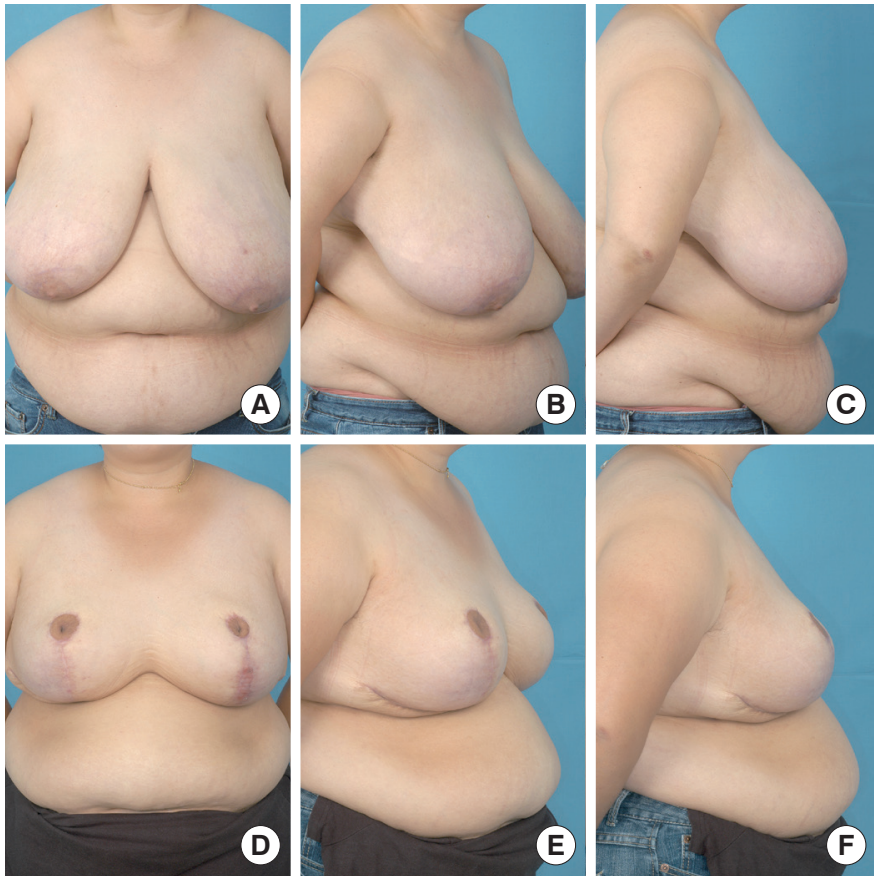

Fig. 6. A case of a reduction mammaplasty. An extremely adipose 35-year-old female patient with gigantomastia. (A, B, C) Preoperative views. (D, E, F) Three-month postoperative views. On the right side, 1,450 $\mathrm{g}$ of breast tissue was removed, while 1,800 $\mathrm{g}$ was removed on the left.

incisional scars with a score of 3.0, which did not represent any significant like or dislike for the appearance of the scar. With regard to symptoms, patients reported an overall score of 3.69 points on a 5 -point scale. More specifically, patients rated improvements with 4 points ('satisfied') for pain, 3.7 points for skin, 3.3 for posture, and 3.6 for shoulder indentation from bra straps. Improvements in exercise/activity were rated as 4 points ('satisfied'). Patients' overall satisfaction with the operation was 3.43 , between 'no strong opinion' and 'satisfied' (Table 6).

\section{DISCUSSION}

All forms of reduction mammaplasty share the primary goal of reducing the mechanical burden of large breasts. However, the secondary objectives vary depending on patient-specific factors, such as preoperative breast asymmetry, projection, and ptosis [8]. The tertiary objectives of avoiding complications further subdivide a single indication (macromastia) into many (macromastia with ptosis, unilateral macromastia, macromastia versus gigantomastia, etc.). As a result of pursuing these secondary and tertiary objectives, a single operation, reduction mammaplasty, has become a numerous set of procedures due to the possible combinations of breast incisions and pedicle designs. Bearing this in mind, the ideal reduction mammaplasty reduces breast volume while resulting in
Table 6. Results of the telephone questionnaire survey $(n=10)$

\begin{tabular}{|c|c|}
\hline & Score \\
\hline 1. Appearance & $3.4^{\mathrm{al}}$ \\
\hline 1.1 While clothed & $3.58^{\mathrm{bl}}$ \\
\hline 1.1.1 & 3.5 \\
\hline 1.1 .2 & 3.5 \\
\hline 1.1 .3 & 3.6 \\
\hline 1.1 .4 & 3.5 \\
\hline 1.1 .5 & 3.8 \\
\hline 1.2 While undressed & $3.22^{\mathrm{bl}}$ \\
\hline 1.2 .1 & 3.3 \\
\hline 1.2 .2 & 3.2 \\
\hline 1.2 .3 & 3.3 \\
\hline 1.2 .4 & 3 \\
\hline 1.2 .5 & 3.4 \\
\hline 1.2 .6 & 3.56 \\
\hline 1.2 .7 & 3 \\
\hline 2. Scar & $3^{\text {a) }}$ \\
\hline 2.1 Length & 3 \\
\hline 2.2 Width & 2.89 \\
\hline 3. Symptoms & $3.69^{\mathrm{al}}$ \\
\hline 3.1 Changes in pain & $4^{\text {b) }}$ \\
\hline 3.1 .1 & 4.1 \\
\hline 3.1 .2 & 4 \\
\hline 3.1 .3 & 4.1 \\
\hline 3.1 .4 & 3.8 \\
\hline 3.2 Changes in skin & $3.72^{\mathrm{bl}}$ \\
\hline 3.2 .1 & 3.67 \\
\hline 3.2 .2 & 3.78 \\
\hline 3.3 Change in posture & $3.33^{\mathrm{bl}}$ \\
\hline 3.3.1 & 3.33 \\
\hline 3.3.2 & 3.33 \\
\hline 3.4 Shoulder indentation & $3.63^{\mathrm{bl}}$ \\
\hline 4. Exercise/activity & $4^{\text {al }}$ \\
\hline 4.1 Aerobic exercise & 3.8 \\
\hline 4.2 Static activities & 4.11 \\
\hline 5. Overall satisfaction & $3.43^{\mathrm{al}}$ \\
\hline 5.1 Surgery & 3.5 \\
\hline 5.2 Recommend to others & 3.3 \\
\hline 5.3 Same operation again & 3.5 \\
\hline
\end{tabular}

${ }^{a}$ Average of the overall category.

${ }^{b)}$ Average of the subcategory.

symmetrical and shapely breasts despite the large variations in secondary and tertiary objectives.

While vertical-incision mastopexy had been described earlier, the modern version of vertical reduction mammaplasty began with Lassus [1], who was in the first generation of surgeons to consider 
the issue of resecting the breast parenchyma and skin en bloc inferiorly, without any undermining of the skin. In addition to liposuction for volume reduction, Lejour [2] modified the Lassus procedure by undermining the skin, which allowed independent manipulation of the underlying parenchyma. The transition from a superior pedicle to a superomedial and medial pedicle, as reported by Hall-Findlay [3], allowed more extensive breast resections through the vertical technique.

With resection masses greater than 1,100 g per breast, complications such as wound dehiscence, NAC necrosis, seroma formation, and excessive scarring have been reported to occur at rates from $7 \%$ to $20 \%[9,10]$. In these patients, NAC repositioning is a significant challenge. The use of NAC free graft techniques only increases the incidence of serious complications, such as partial or complete nipple loss (up to 18\%). In addition, the complete loss of nipple sensation and poor nipple projection are recognized problems [11,12].

While the vertical reduction mammaplasty technique has been validated for mild-to-moderate breast hypertrophy, the inverted-T incision and inferior pedicle have been recommended for resections greater than a kilogram. A tendency to cause long vertical scars extending below the inframammary crease and dog-ears at the lower end of the scar has led to the addition of short horizontal scars [13, 14]. Using the established method of vertical reduction mammaplasty with few modifications and a superomedial pedicle, such complications can be diminished, while still achieving cosmetically satisfactorily breasts. The advantages of a superomedial pedicle include reliable circulation with the capacity of a long nipple-areola distance transposition and the ability to better shape the breast. One of the goals of breast reduction is to reduce the lateral fullness caused by dense breast tissue in the upper outer quadrant, which can be achieved with a superomedial pedicle [15]. Problems can arise for NAC viability when the length of the pedicle is excessive, especially for large breasts requiring more than $600 \mathrm{~g}$ of reduction. At our institution, we design the pedicle closer to the superior side when the amount of the reduction is small, and closer to medial side for larger reductions. Previous studies have reported that the superomedial dermoglandular pedicle base located between the areolar opening and vertical limb should be at a ratio of 1:1 [16], but the authors only included 1 to $2 \mathrm{~cm}$ of the pedicle base. This was done because shaping the NAC is more difficult when the pedicle base is included in the areolar opening, as the de-epithelialized base crumbles when closing the mosque dome. Moreover, the reason why the pedicle base should be included in the areola opening is that if the whole pedicle is included in the vertical limb, the formation of the inferior fullness causes pseudoptosis due to uncomfortable pedicle insetting, especially in rotation. The breast tissue and skin were removed en bloc, but the pattern of the parenchymal resection was determined by the amount of the parenchymal resection. When the resection was small, the parenchyma was excised only in the vertical direction from the incision line. In con- trast, in larger resections, the parenchyma was resected in a beveled fashion, from the outer caudal direction (Fig. 3). Inferiorly, excessive subcutaneous tissue can lead to dog-ear formation.

Although this study reviewed a relatively small study group, the survey responders $(n=10)$ reported overall satisfaction (satisfaction score, 3.43) with having undergone reduction mammaplasty. While conventional vertical reduction mammoplasty has been reserved for reductions $<600 \mathrm{~g}$ [17], the modified method has allowed reductions $>600 \mathrm{~g}$, with a maximum of $1,800 \mathrm{~g}$ and $1,450 \mathrm{~g}$ in one patient. It is interesting to note that NAC sensibility was retained in the reductions performed with a superomedial pedicle $(n=18)$. Previously, Spear et al. [18] reported that no significant differences in breast sensation were found across various methods of mammaplasty, among which vertical reduction mammaplasty was reserved for reductions of approximately $460 \mathrm{~g}$ (range, 340-590 g). In contrast, we were able to perform reductions greater than $600 \mathrm{~g}$ using this method, with most patients recovering NAC sensibility by 1 year postoperatively. However, the patient with the greatest amount of reduction reported subjectively unsatisfactory outcomes ( 3 out of 10 on an ordinal scale) regarding NAC sensation 60 months after the operation. This patient represented the index case of vertical reduction mammaplasty for reductions greater than $600 \mathrm{~g}$, and patients subsequent to this case reported full recovery of sensation, including a patient who underwent reductions of 840 and $994 \mathrm{~g}$ in the left and right breast, respectively.

Sensory loss in the NAC is a well-known complication of reduction mammaplasty. In 2002, when describing the medial dermoglandular pedicle technique, Hall-Findlay [3] concluded that the sensation of the NAC remained unchanged when a medial pedicle was used, unlike the inferior pedicle technique. A detailed description of the innervation of the nipple and areola was published by Schlenz et al. [19] in 2000. The most constant innervation pattern was innervation by the fourth lateral cutaneous branch (79\%) and by the third and fourth anterior cutaneous branches (57\%) of the intercostal nerve. The lateral cutaneous branches took a deep course within the pectoral fascia and reached the nipple from its posterior surface in $93 \%$ of the dissected breasts. In $7 \%$ of the dissected breasts, the lateral cutaneous branches took a superficial course within the subcutaneous fat and reached the nipple from the lateral side. In a study regarding nipple sensitivity following reduction mammaplasty, medial pedicle reduction mammaplasty was associated with complete sensory recovery in 68 of 79 breasts (86\%) [20]. In 2010, Michelle le Roux et al. [21] reported the course of the nerve supply of the NAC in an anatomical study of 11 female cadaveric breast specimens. It is of great significance that the nerves supplying the NAC run in a deep plane laterally, but are completely superficial within a distance of $3 \mathrm{~cm}$ from the nipple. This suggests that it is necessary to preserve superficial tissue in the design of a neurovascular pedicle of the preservation of sensibility in the nipple. To prevent the complete loss of sensation, the skin should be de-epitheli- 
alized, but a 1-cm cuff of tissue should be preserved around the edge of the new areola. The diameter of the pedicle base surrounding the NAC was $6.5 \mathrm{~cm}$, which was well within the $3-\mathrm{cm}$ radius described by Michelle le Roux et al. The full-thickness, superomedially based pedicle was then carried directly down to the chest wall. The dissection was carried straight down, but the pectoralis fascia was not exposed. At this time, some breast parenchymal tissue was left in continuity to the pectoralis fascia to preserve the blood and nerve supply.

In our experience, refinements in the vertical mammaplasty technique with the superomedial dermoglandular pedicle allowed for mammaplasty with reductions ranging from 76 to $1,800 \mathrm{~g}$, while maintaining patient satisfaction and sensory preservation in the NAC.

The limitations of our study are that the study sample size was small, the response rate was not high, sensory assessment was subjective, and that the incision needed to be extended laterally in patients with gigantomastia requiring reduction of more than $1,100 \mathrm{~g}$. Subsequent studies will require quantitative methods of sensory assessment, such as pressure-specified sensory devices [16].

\section{PATIENT CONSENT}

Patients provided written consent for the use of their images.

\section{REFERENCES}

1. Lassus C. A technique for breast reduction. Int Surg 1970;53:69-72.

2. Lejour M. Vertical mammaplasty and liposuction of the breast. Plast Reconstr Surg 1994;94:100-14.

3. Hall-Findlay EJ. Vertical breast reduction with a medially-based pedicle. Aesthet Surg J 2002;22:185-94.

4. Spear SL, Howard MA. Evolution of the vertical reduction mammaplasty. Plast Reconstr Surg 2003;112:855-68.

5. Dancey A, Khan M, Dawson J, et al. Gigantomastia--a classification and review of the literature. J Plast Reconstr Aesthet Surg 2008;61:493502.

6. Amini P, Stasch T, Theodorou P, et al. Vertical reduction mammaplasty combined with a superomedial pedicle in gigantomastia. Ann Plast
Surg 2010;64:279-85.

7. Nymann P, Hedelund L, Haedersdal M. Long-pulsed dye laser vs. intense pulsed light for the treatment of facial telangiectasias: a randomized controlled trial. J Eur Acad Dermatol Venereol 2010;24:143-6.

8. Lapid O, de Groof EJ, Corion LU, et al. The effect of breast hypertrophy on patient posture. Arch Plast Surg 2013;40:559-63.

9. Heine N, Eisenmann-Klein M, Prantl L. Gigantomasty: treatment with a short vertical scar. Aesthetic Plast Surg 2008;32:41-7.

10. Landau AG, Hudson DA. Choosing the superomedial pedicle for reduction mammaplasty in gigantomastia. Plast Reconstr Surg 2008;121: 735-9.

11. Townsend PL. Nipple sensation following breast reduction and free nipple transplantation. Br J Plast Surg 1974;27:308-10.

12. McGregor JC, Hafeez A. Is there still a place for free nipple areolar grafting in breast reduction surgery? A review of cases over a three year period. J Plast Reconstr Aesthet Surg 2006;59:213-8.

13. Marchac D, de Olarte G. Reduction mammaplasty and correction of ptosis with a short inframammary scar. Plast Reconstr Surg 1982;69: 45-55.

14. Pallua N, Ermisch C. "I" becomes "L": modification of vertical mammaplasty. Plast Reconstr Surg 2003;111:1860-70.

15. Hall-Findlay EJ. Pedicles in vertical breast reduction and mastopexy. Clin Plast Surg 2002;29:379-91.

16. Hall-Findlay EJ. Vertical breast reduction. Semin Plast Surg 2004;18: 211-24.

17. Hall-Findlay EJ. Vertical reduction mammaplasty. In: Thorne $\mathrm{CH}$, Beasley RW, Aston SJ, et al., editors. Grabb and Smith's plastic surgery. 6th ed. Philadelphia, PA: Lippincott Williams and Wilkins; 2007. p.604-13.

18. Spear ME, Nanney LB, Phillips S, et al. The impact of reduction mammaplasty on breast sensation: an analysis of multiple surgical techniques. Ann Plast Surg 2012;68:142-9.

19. Schlenz I, Kuzbari R, Gruber H, et al. The sensitivity of the nipple-areola complex: an anatomic study. Plast Reconstr Surg 2000;105:905-9.

20. Nahabedian MY, Mofid MM. Viability and sensation of the nipple-areolar complex after reduction mammaplasty. Ann Plast Surg 2002;49: 24-31.

21. Michelle le Roux C, Kiil BJ, Pan WR, et al. Preserving the neurovascular supply in the Hall-Findlay superomedial pedicle breast reduction: an anatomical study. J Plast Reconstr Aesthet Surg 2010;63:655-62. 